\title{
LA EXCEPCIÓN EN EL DERECHO
}

Bernardo García CAMINO

\author{
Javier RASCADO PÉREZ
}

Universidad Autónoma de Querétaro (México)*

«Exceptio confirmat regulam in casibus non exceptis» (La excepción confirma la regla en los casos no exceptuados)

Principio jurídico ${ }^{1}$

\begin{abstract}
RESUMEN
En el presente trabajo analizaremos la figura de la excepción, empezando por delimitar a qué excepción jurídica nos referimos Posteriormente revisaremos cómo considera el garantismo ferrajoliano a la excepción. A continuación, bajo la Critical Legal Studies, buscaremos justificar su existencia en el Derecho y aplicación a un caso, concluyendo con la explicación correspondiente a la escuela de la retórica y la racionalidad.
\end{abstract}

Palabras clave: excepción, garantismo, Critical Legal Studies, retórica, racionalidad.

\section{ABSTRACT}

In this piece of work we will study the figure of exception, starting by defining the legal exception we are referring to. We will then look at how exception is viewed by Luigi Ferrajoli's Garantism. Next, under the Critical Legal Studies we will try to justify its existence in Law and how it is applied to a given case. We will finish with the subsequent explanation related to the School of Rhetoric and Rationality.

Keywords: Exception, Garantism, Critical Legal Studies, Rhetoric, Rationality.

* Alumnos egresados del programa de doctorado en Derecho de la Facultad de Derecho de la Universidad Autónoma de Querétaro (México). El presente trabajo forma parte de las investigaciones realizadas en el tema de los autores dentro del rubro institucional «Constitucionalismo y poder público», con la supervisión de los integrantes del cuerpo académico don Juan Ricardo Jiménez Gómez, doña Gabriela Nieto Castillo y don Enrique Rabell García.

${ }^{1} \mathrm{Al}$ menos así lo considera Víctor José Herrera Llorente, Diccionario de expresiones y frases latinas, Madrid, Gredos, 2001. 


\section{ZUSAMMENFASSUNG}

In der vorliegenden Arbeit untersuchen wir die Rechtsfigur der Einrede und definieren, auf welche juristische Einrede wir uns hier beziehen wollen. Anschließend untersuchen wir, wie der Garantismus von Luigi Ferrajoli die Einrede versteht. Dann, unter Bezugnabme auf die Critical Legal Studies, versuchen wir das Vorhandensein der Einrede im Recht zu rechtfertigen und wenden sie abschließend auf einen konkreten Fall an, in welchem wir uns auf die bereits genannte Schule der Rhetorik und Rationalität beziehen.

Schlüsselwörter: Einrede, Garantismus, Critical Legal Studies, Rhetorik, Rationalität.

SUMARIO: I. INTRODUCCIÓN.-II. LA ESCUELA GARANTISTA.-III. LA ESCUELA CRÍTICA DEL DERECHO.-IV. RETÓRICA Y RACIONALIDAD JURÍDICA.-V. CONCLUSIÓN.-VI. BIBLIOGRAFÍA.

\section{INTRODUCCIÓN}

Delimitando el campo conceptual, consideramos, al decir de Piaget, que los problemas centrales de la epistemología son la naturaleza y las condiciones previas de las relaciones entre sujeto - ser cognoscente- y objeto - proceso o fenómeno sobre el cual el sujeto desarrolla su actividad cognitiva- por medio de los cuales es posible obtener conocimientos válidos o verdaderos ${ }^{2}$.

Hablar de epistemología jurídica, de su gnoseología, es a sabiendas de que, al ir cambiando de corrientes de pensamiento, también se irá modificando aquello que es considerado el objeto de la ciencia jurídica, toda vez que las distintas ideologías o escuelas irán colocando en distintos puntos lo que consideran la esencia y la razonabilidad, así como la manera de probarse o sustentarse como verdad. De esta forma, hechos, conductas, la norma, la justicia, los valores o los sujetos, entre otros, podrán ser considerados los componentes esenciales del Derecho y, según se decanten a favor de alguno de ellos, serán los distintos matices que se señalan como la razón de existir de la ciencia jurídica.

Coloquialmente consideramos que existe excepción cuando algo no es conforme a las reglas, que no se adecúa a los supuestos, incluso cuando se

\footnotetext{
${ }^{2}$ Jean Piaget, Psicología y epistemología, traducción de Francisco J. Fernández, México, Planeta Agostini, 1986, citado por Víctor Manuel Rojas Amandi, Tres paradigmas de la epistemología jurídica, México, UNAM, disponible en http://www.juridicas.unam.mx/publica/librev/rev/facdermx/cont/252/art/art14.pdf (consultado el 14 de abril de 2011).
} 
aparta de la condición normal de los de su especie, o que ocurre rara vez o de manera incidental.

Históricamente el ser humano le ha dado un trato similar. En la antigüedad la existencia de eclipses, terremotos, variaciones de pigmentación en la piel o en los ojos, la epilepsia o cualquier otro fenómeno de la naturaleza que se salía de la cotidianeidad era explicado de formas muy variadas: por enojo o alegría de los dioses en forma de castigos o premios, premoniciones, etc.; cuando avanzaba la ciencia y se descubrían y podían explicar las causas de tales fenómenos se advierte que, si bien no eran de acontecer frecuente, no por ello resultaban anormales.

En los diferentes tipos de conocimiento recibe tratamientos distintos. Por ejemplo, en las ciencias naturales se habla, en la bioquímica y en la genética, del azar y la necesidad, conceptos que explican distintas variables que pueden resultar en la evolución de los organismos vivos y que, derivado del azar genético, les resulta favorable para resolver determinada necesidad, lo cual permite la selección natural; por otra parte, de las investigaciones genéticas se determina el principio de universalidad del código genético, siendo su única excepción el código genético mitocondrial, de manera que en algunos organismos, los aminoácidos determinados por el mismo triplete o codón son diferentes en el núcleo y en la mitocondria ${ }^{3}$. Una excepción a las condiciones genéticas de un organismo puede ser su albinismo, en el cual su organismo, por mutación genética, no produce melanina, y ambos padres, como portadores del gen recesivo, los transmiten, aunque no en todos los individuos se manifiesta, dándose el resultado como azar.

También en áreas de la teología se habla de excepciones. Joseph Ratzinger describe el concepto de persona y señala:

«También me parece una limitación la que sufrió Tomás de Aquino en este ámbito, que en la teología avanza en el plano de la existencia con Ricardo de San Víctor, pero tratándolo como una excepción teológica, mientras en la filosofía permanece fiel al planteamiento precristiano con el concepto de persona de Boecio. Con ello no se realiza la aportación de la fe cristiana a la totalidad del pensamiento humano, puesto que se queda en una excepción teológica, aunque el sentido de esta novedad consista en poner en cuestión la totalidad del pensamiento humano y conducirlo por nuevos caminos. Con esto estamos ante el segundo malentendido consis-

\footnotetext{
${ }^{3}$ Código genético, características y desciframiento, disponible en bttp://www.ucm.es/ info/genetica/grupod/Codigo/Codigo\%20ge\%20netico.htm (consultado el 29 de noviembre de 2011).
} 
tente en la idea de que Cristo constituya una excepción ontológica irrepetible; considerándola, pues, como tal, es objeto de altas especulaciones intelectuales, pero su figura debe permanecer estrictamente delimitada en su calidad de excepción a la regla, sin mezclarla con el resto de temas con los que se ocupa el pensamiento humano» ${ }^{4}$.

A pesar de encontrarse en el ánimo popular la idea de que las excepciones son confirmatorias de la norma, no es sino derivado del abuso en el lenguaje al generalizar las cosas, usándose como justificante de un caso anómalo y contrario al de la costumbre: si aseguramos que el autobús siempre llega tarde y en esa ocasión llega a tiempo, nos será fácil aducir que la excepción confirma la regla, cuando en realidad a veces llega puntual y a veces impuntual. La existencia de un cuervo blanco no es la confirmación de que todos los cuervos sean negros. Por el contrario, será la confirmación de que hay cuervos negros y cuervos blancos ${ }^{5}$.

Como hemos señalado, no nos limitaremos, por ende, a una sola corriente ideológica jurídica sin profundizar aún en las características de la ciencia del Derecho. Partiremos de la idea de que el Derecho se conforma por normas; debemos aceptar la existencia también de la excepción bajo distintas modalidades, las cuales trataremos de distinguir.

Existen excepciones contempladas como normas, es decir, en el corpus normativo se incluyen disposiciones prohibitivas y además excepciones a dichos postulados jurídicos que implican, si bien no necesariamente una permisividad, sí la ausencia de sanción; por ejemplo, hay una norma que sanciona el homicidio y le establece una penalidad de siete a quince años de prisión ${ }^{6}$. El mismo ordenamiento señala la inexistencia de delito - - , por ende, de pena- a quien cometa homicidio en legítima defensa o estado de necesidad ${ }^{7}$; por tanto, en el primer supuesto la ley prevé una conducta indebida y a la vez encuentra razones de permitirla bajo distintas circunstancias, como lo es el segundo supuesto, rompiendo con ello una regla «general» de sancionar al que prive de la vida a otro. De esta forma encontramos una excepción a la que denominaremos normada.

\footnotetext{
${ }^{4}$ Véase Concepto de persona en la teología, conferencia pronunciada por el cardenal Ratzinger en un congreso sobre el concepto de persona en la pedagogía y en las ciencias auxiliares, disponible en http://www.scribd.com/doc/56011791/Ratzinger-Persona-en-teologia (consultado el 27 de noviembre de 2011).

5 Téngase presente el «problema de Hume» descrito por Karl Popper, el contenido científico de la falsación.

${ }^{6}$ Código Penal para el Estado de Querétaro, art. 125.

7 Ibid.
} 
Otra variable de excepción normada es cuando la ley, más que encontrar una justificación a la conducta, rompe con una de sus características: la generalidad, y hace un distingo para cierto tipo de personas. Por ejemplo, en la Constitución mexicana se establece el concepto de multa y señala un tope, de manera específica a favor de jornaleros, obreros y trabajadores, en el que aplicará sólo un día de multa ${ }^{8}$, generando una excepción respecto de aquellos que no cuentan con dicha condición o se ajustan al supuesto previsto, de esta forma se genera un subgrupo, de nueva cuenta general, pero al que se excluye de una condición de aplicación de la norma.

Otro de los supuestos de esta categoría de normada es cuando la ley establece una prohibición y, bajo el significado de incidental o de salvedad, tolera un supuesto, quitando a la prohibición su carácter de absoluta y convirtiéndola en relativa. Por ejemplo, y de nuevo refiriéndonos a la Constitución ${ }^{9}$, prohíbe que los ministros de la Suprema Corte de Justicia, los magistrados de Circuito, los jueces de Distrito, los respectivos secretarios y los consejeros de la Judicatura Federal, así como los magistrados de la Sala Superior del Tribunal Electoral, acepten o desempeñen empleos o encargos de la Federación, Estados, del Distrito Federal o de particulares, con excepción de los cargos no remunerados en asociaciones científicas, docentes, literarias o de beneficencia. La intencionalidad de este supuesto es garantizar una imparcialidad, y por ello prohíbe que se trabaje por otro sueldo, pero permite, cuando no se les paga, que laboren en cuestiones de interés general.

Estos tres primeros casos son de bajo impacto jurídico, ya que la excepción forma parte de la ley misma y la propia norma señala expresamente qué alcance tiene.

Un segundo tipo de excepciones son aquellas que hacen que la misma norma las disponga. Por ejemplo, si una señal de tránsito establece la prohibición de estacionar los domingos, implícitamente contiene el permiso de aparcar el resto de los días de la semana; en este caso, la norma que se presenta en sentido negativo es, en sí misma, la permisión a hacerlo el resto de los días. A este tipo de excepción la llamaremos permisiva.

En este caso, de nuevo, es mínimo el impacto jurídico. Si bien la ley no es clara, permite una inferencia lógica sencilla que sirve para desentrañar su significado, es decir, ocurre en circunstancias ordinarias.

\footnotetext{
${ }^{8}$ Constitución política de los Estados Unidos Mexicanos, art. 21.

${ }^{9}$ Ibid., art. 101.
} 
Hay otro tipo de excepción que, contraria a las antes señaladas, implica cuestiones distintas. Para plantearla debemos aceptar que la razón justificadora del Estado de Derecho es proporcionar seguridad jurídica. Para conseguirlo uno de los supuestos exigidos es que la conducta en la comunidad sea normada.

Cuando se establece en normas la regulación de las conductas, éstas se encuentran previamente delineadas, estableciendo con toda claridad y precisión qué está prohibido y qué está permitido. La condición que se genera es la certeza. A partir de lo anterior surgen otros principios de distintas índoles que no son objeto de este estudio, como son la irretroactividad o las lagunas o antinomias jurídicas.

La certeza se puede establecer en un ordenamiento en la medida en que, como se mencionó, regula conductas; sin embargo, lo hace desde la cotidianeidad, es decir, hay un orden establecido y protegido por la misma regulación para conservarlo.

Pero hay casos en que la normalidad y el orden se pueden ver afectados por circunstancias que se consideran emergencias o imprevistos, y resulta imperiosa la necesidad de recuperar la seguridad y la estabilidad. Para ello puede suceder que no haya disposición legal alguna que sirva para atender dicho conflicto, o, como segundo supuesto, que la disposición que se encuentre sea poco clara, o, por último, que la solución que se requiere para atender el problema sea contraria y prohibida por las normas.

Entonces, si a un problema determinado no es posible darle solución bajo los sistemas ordinarios que rigen en el país, conformados, según se mencionó, por normas que regulan conductas, y que estas normas ordinarias pueden ser la separación de funciones y el respeto a los derechos humanos, y que las circunstancias revisten tal magnitud que ponen en riesgo la existencia misma del Estado o de la comunidad; si además agregamos que las leyes prohíben las medidas necesarias para afrontarlo, pues supondría alterar los mencionados como sistemas ordinarios, dándole facultades al ejecutivo para legislar rompiendo la división de poderes o restringir la plena vigencia de los derechos humanos (normativamente en sentido estricto es muy sencillo), la norma no permitiría ir contra sí misma aceptando su trasgresión, pero subsiste el cuestionamiento de si se trata de una realidad fáctica o de una cuestión de la norma, y, por ende, del Derecho, pudiendo preguntarnos si este tipo de excepción se encuentra dentro o fuera de la norma.

Otra explicación se refiere a lo que un Estado amenazado responde haciendo todo aquello que no tendría justificación en tiempos nor- 
males, usan(do) justificaciones que sólo funcionan in extremis, encarando problemas tan severos que tienen que violar sus propios principios para salvarse.

Cuando la problemática es tan grave que pone en riesgo la existencia del ordenamiento (al espacio de aplicación de la norma, a sus creadores, aplicadores o a sus destinatarios), la excepción no debe ser considerada una opción o una facultad, sino una obligación o un imperativo, aun cuando las medidas impliquen el rompimiento del orden jurídico normativo ordinario ${ }^{10}$. Se abren dos alternativas, una de corte extralegal, en la cual se propone aceptar que la conducta del gobernante será excepcional y sometida a un juicio público por su actuar sin que se permita que la ley se «contamine» por decisiones no previstas; la segunda opción, considerada legalista, apuesta a la responsabilidad del gobernante de apegarse al Estado de Derecho y asumir la existencia de controles jurisdiccionales y políticos en los otros dos poderes que impidan el exceso y el abuso del poder.

$\mathrm{Al}$ decir de Vázquez Irizarry: «No es posible acomodo alguno entre el Estado de Derecho y la excepción. Que el ordenamiento pretenda reconocer y aceptar una situación de excepcionalidad donde es necesario transgredir el orden establecido está en detrimento con los supuestos que sustentan un Estado de Derecho. El quebranto de la ley no puede ser avalado por la ley sin que la legitimidad de ésta no resulte lacerada» ${ }^{11}$.

Se pone así a prueba la fidelidad al sistema normativo y legal, ya que habrá soluciones que no se permitan por las propias normas. Una de las propuestas iniciales es flexibilizar la ley y admitir supuestos, toda vez que no se puede atender la anormalidad con los criterios ordinarios, pero siempre manteniendo los diversos controles para evitar el abuso de poder. La forma de establecer los controles sigue siendo la mayor duda de la opción. Como se mencionó, hay opciones legales y extralegales, y cuando la situación de emergencia se aplica sin la correspondiente declaratoria, para que sea legal no hay forma de activar a su vez los controles preestablecidos en la propia norma, quedando sólo que, sin que sean leyes propiamente

\footnotetext{
10 «Constraining the executive by ordinary rules of law when the state faces a mortal challenge is to deprive the state of the wherewithal to protect and defend itself in the ways it may need to in order to survive» (Kim LANE SCHEPPELE, «Legal and Extralegal Emergencies», en The Oxford Handbook of Law And Politics, Oxford, Oxford Univesrsity Press, 2010).

11 William VÁzQUEZ IRIZARRY, Excepción y necesidad: la posibilidad de una teoría general de la emergencia, disponible en bttp://www.law.yale.edu/documents/pdf/sela/VazquezIriza$r r y \_S p \_C V . p d f$ (consultado el 29 de octubre de 2010). Hay versión en inglés y en español; en la primera se maneja el término Rule of Law — que para algunos no admite traducción exacta- y en la versión en español lo refiere como Estado de Derecho.
} 
hablando, se apliquen los principios que le otorgan a un sistema la característica de Estado de Derecho.

Carl Schmitt argumenta: «Tal excepción era asimismo fundamental para confirmar la existencia de la regla, pues la excepción es más importante que la regla, ya que la regla no prueba nada y la excepción lo prueba todo: no sólo confirma la regla, sino también su existencia, que deriva sólo de la excepción. En la excepción el poder de la vida real irrumpe tras la corteza de un mecanismo que ha devenido entorpecido por su repetición» ${ }^{12}$.

Bajo el supuesto de que el Derecho se dicta a través de las resoluciones judiciales, hay que destacar que cabe una sentencia en la medida en que existe un incumplimiento a las leyes. En otras palabras, el Derecho surge en los enunciados que provienen de la excepción del cumplimiento de las obligaciones estipuladas en las normas.

Cabe hacer la acotación de que la impunidad no debe ser contemplada como excepción, si bien la misma implica la inaplicación de la norma no lo es por problemas inherentes a la misma, sino de aquellos responsables de ejecutar sus mandatos. Los problemas de eficacia en este caso corresponden a las personas y no a las leyes.

Para este trabajo nos referiremos a las excepciones bajo la última explicación, como rompimiento del sistema jurídico, tanto en las consideraciones legales como en las extralegales.

\section{LA ESCUELA GARANTISTA}

Luigi Ferrajoli, autor neopositivista italiano, señala que el objetivo de la semántica de la teoría del Derecho es identificar las cosas o experiencias y que pueden ser interpretadas y verificadas. Para él, normativismo implica la asignación a las normas como referencia semántica de los discursos de la ciencia jurídica. Si bien distingue entre la verdad fáctica, la verdad jurídica y la verdad judicial, se circunscribe a los ámbitos de refutabilidad en la medida en que la verdad judicial, como mezcla de verdades fácticas con jurídicas, se convierte en verdad absoluta en la medida de la irrevocabilidad de las sentencias. Todo su estudio es normativo, de corte garantista, en la medida que propugna por una priorización de las garantías y su respeto. Para él, la excepción es una crisis del Derecho, y manifiesta:

${ }^{12}$ Carl Schmitt, Teología política, Madrid, Trotta, 2009, p. 17. 
«Crisis de la legalidad, es decir, del valor vinculante asociado a las reglas por los titulares de los poderes públicos [...] El segundo aspecto de la crisis, sobre el que más se ha escrito, es la inadecuación estructural de las formas del Estado de Derecho a las funciones del Welfare State, agravada por la acentuación de su carácter selectivo y desigual que deriva de la crisis del Estado social. Como se sabe, esta crisis ha sido con frecuencia asociada a una suerte de contradicción entre el paradigma clásico del Estado de Derecho, que consiste en un conjunto de límites y prohibiciones impuestos a los poderes públicos de forma cierta, general y abstracta, para la tutela de los derechos de libertad de los ciudadanos, y el Estado social, que, por el contrario, demanda a los propios poderes la satisfacción de derechos sociales mediante prestaciones positivas, no siempre predeterminables de manera general y abstracta y, por tanto, eminentemente discrecionales, contingentes, sustraídas a los principios de certeza y estricta legalidad, y confiadas a la intermediación burocrática y partidista. Tal crisis se manifiesta en la inflación legislativa provocada por la presión de los intereses sectoriales y corporativos, la pérdida de generalidad y abstracción de las leyes, la creciente producción de leyes-acto, el proceso de decodificación y el desarrollo de una legislación fragmentaria, incluso en materia penal, habitualmente bajo el signo de la emergencia y la excepción. Es claro que se trata de un aspecto de la crisis del Derecho que favorece al señalado con anterioridad. Precisamente, el deterioro de la forma de la ley, la falta de certeza generalizada a causa de la incoherencia y la inflación normativa, y, sobre todo, la falta de elaboración de un sistema de garantías de los derechos sociales equiparable, por su capacidad de regulación y de control, al sistema de las garantías tradicionalmente predispuestas para la propiedad y la libertad, representan, en efecto, no sólo un factor de ineficacia de los derechos, sino el terreno más fecundo para la corrupción y el arbitrio» ${ }^{13}$.

El autor italiano establece que la excepción es un área de pérdida para el Derecho, en la cual se devalúa y se afecta al Estado de Derecho y al estado de satisfacción. Y es que considera que una proposición es jurídicamente verdadera si, y sólo si, enuncia el sentido de una norma jurídica vigente.

Como hemos expuesto con anterioridad, la excepción es el rompimiento de las normas jurídicas, por ende, las proposiciones del estado de excepción carecerán, para Ferrajoli, de toda validez por no ajustarse a las normas vigentes, pero fáctica, jurídica e incluso judicialmente podrán estar ahí, sin que pueda explicar su contenido.

${ }_{13}$ Luigi FerRajoli, Derechos y garantías: la ley del más débil, Madrid, Trotta, 1994, p. 16. Las cursivas son nuestras. 
Sin embargo, consideramos que la excepción es un espacio de creación de normas jurídicas. No sólo aquellas que se ocupan de resolver el problema, sino aquellas que servirán para convertir aquella situación que tomó por sorpresa al orden cotidiano en una regulación que, a futuro, evite la necesidad de la medida extrema, es decir, el uso de la crisis como un nuevo espacio de regulación preventiva, de expansión y fortalecimiento del Derecho. No se debe soslayar que en los casos en que la excepción, además de extralegal, sea usada únicamente con fines de detentar el poder y hacerlo de forma absoluta, puede parecer contraria al orden jurídico. De esta foma, al igual que lo mencionamos con la impunidad, lo que estaría en crisis serían los funcionarios, los destinatarios y no la norma en sí misma.

Por otra parte, el uso de la previsión legal para acceder a los estados de excepción implica, en sí mismo, una garantía, ya que se establecen mecanismos de control, también extraordinarios, para continuar con la limitación del poder, incluidas las figuras que conforman el Derecho procesal constitucional, además de que en el texto de la norma - lo que defiende en sí Ferrajoli como positivista que es- le señalará límites temporales y materiales de acción que garantiza, si bien no el respeto absoluto del sistema normativo por la existencia de la emergencia, que tampoco se dé un rompimiento total.

Giorgio Agamben ubica el estado de excepción como el momento del Derecho en el que, para garantizar su existencia, el orden jurídico se suspende. Ahora bien, esta forma que impera durante el siglo XX «instituye una guerra civil legal que sólo se sostiene a través de la íntima relación entre anomia y Derecho, entre vida y norma ${ }^{14}$. Lo anterior cobra relevancia en el pensamiento de Agamben cuando argumenta que «el totalitarismo moderno puede ser definido como la instauración, a través del estado de excepción, de una guerra civil legal, que permite la eliminación física no sólo de los adversarios políticos, sino de categorías enteras de ciudadanos que, por cualquier razón, resultan no integrables en el sistema político» ${ }^{15}$.

Por lo anterior, el enfoque del florentino es parcial: niega la existencia de la necesidad fáctica de la existencia de la emergencia y de su conveniencia para la salvaguarda del propio sistema jurídico, con lo que podemos señalar que su visión sería similar a negar una intervención quirúrgica al considerarla lesión, sin apreciar que el beneficio será mayor, que lesionándolo sanará y que si no se interviene drásticamente correrá mayor peligro, incluida la muerte.

\footnotetext{
${ }^{14}$ Giorgio Agamben, Estado de excepción, Homo Sacer, II, 1, Valencia, Pre-textos, 2003.

15 Ibid.
} 


\section{LA ESCUELA CRÍTICA DEL DERECHO}

Para el análisis de la excepción en el Derecho, a la luz de la Critical Legal Studies, siguiendo la dinámica de Duncan Kennedy, uno de sus exponentes, nos proponemos usar una técnica parecida a la que él plantea en su obra Libertad y restricción en la decisión judicial ${ }^{16}$ con algunas variantes. Las diferencias de aplicación del Derecho entre el sistema anglosajón al que está acostumbrado y de los márgenes de los jueces difieren a los del sistema mexicano. Esto aunado a que los mecanismos que se pueden utilizar también varían, nos dan la pauta para seleccionar como tópico en el cual expliquemos esta corriente ideológica el uso de la excepción como método para acceder «a la sentencia a la cual quiero llegar», por lo que revisaremos hechos mexicanos y norteamericanos de los respectivos presidentes en los símiles de Felipe Calderón y George W. Bush; permitiéndonos hacer saltos, a veces, de uno a otro, sobre todo cuando se cita a la doctrina extranjera en los supuestos que serán revisados; por otra parte, Kennedy da las variables de cómo podía ir construyendo una sentencia, lo que trataremos de hacer es ver cómo la construyeron.

El caso en estudio es la guerra que iniciaron ambos: en el caso mexicano, la guerra contra el narcotráfico, y en el caso norteamericano será la guerra contra el terrorismo ${ }^{17}$, tratando de comprobar que, al igual que en el caso americano, la guerra contra el narcotráfico mexicano fue una estrategia de legitimación presidencial, generando un estado de excepción.

México mantuvo setenta años de estabilidad política sustentados en la existencia de un partido político que fue hegemónico. Sus reglas - escritas o no, legales o extralegales- le permitieron ser calificado como la «dictadura perfecta» ${ }^{18}$ porque las facultades metaconstituciona-

16 Disponible para su lectura en http://duncankennedy.net/documents/Photo $\% 20$ articles/Libertad\%20y\%20Restriccion\%20en\%20la\%20Decision\%20Judicial_Estudio\%20 Introductorio.pdf (consultado el 13 de agosto de 2012).

${ }_{17}$ No soslayamos la posibilidad de otras facetas en el caso de la guerra contra el terrorismo, la posibilidad de reactivación económica, los intereses petroleros y de los grandes complejos militares industriales de aquel país; sin embargo, en ambos casos existió el cuestionamiento postelectoral.

18 «México es la dictadura perfecta. La dictadura perfecta no es el comunismo. No es la URSS. No es Fidel Castro. La dictadura perfecta es México», dijo un Vargas Llosa que a estas alturas ya parecía de nuevo el político intenso de hace unos meses. «México — siguióes la dictadura camuflada [...] Tiene las características de la dictadura: la permanencia no de un hombre, pero sí de un partido. Y de un partido que es inamovible» [El País, México-Madrid, 1 de septiembre de 1990, disponible en bttp://www.elpais.com/articulo/cultura/ 
les ${ }^{19}$ del presidente le permitían el dominio absoluto no sólo del poder ejecutivo, sino también del legislativo y del judicial. Los poderes de los Estados y de las empresas y organismos descentralizados le dejaban decidir absolutamente todo lo concerniente al país, es decir, contaba con una libertad absoluta.

El sistema presidencialista mexicano fue consolidándose. Un presidente y un partido dominante requerían de diversos actores que aplaudieran y fortalecieran al mismo régimen; así, en el ámbito del Derecho, no sólo la Suprema Corte de Justicia de la nación, a través de la jurisprudencia, justificó cualquier acto del presidente, sino también la tradición doctrinal mexicana generó todos los argumentos que le hicieron falta al presidente para que sus actos quedaran revestidos de toda «legalidad» a través de interpretaciones publicadas nacional o internacionalmente ${ }^{20}$. Entonces el Derecho quedó al servicio del mismo sistema.

Desde 1988 el sistema priista se empezó a tambalear; el cuestionamiento del triunfo de su candidato, la «caída del sistema» del cómputo electoral y la pérdida de los porcentajes abrumantes del votos provocaron que el presidente Carlos Salinas de Gortarí (198) buscara legitimar su mandato a través de acciones políticas o reformas trascendentes ${ }^{21}$.

La alternancia política se inició cuando en 1997 el PRI pierde por primera vez la mayoría en la Cámara de Diputados bajo el régimen presidencial de Ernesto Zedillo y, posteriormente, en 2000 el partido Acción Nacional con el candidato Vicente Fox gana la Presidencia de la República. De alguna forma podemos considerarlo como el inicio de las restricciones de las facultades metaconstitucionales del presidente.

Hubo un cambio de titular del poder ejecutivo, de ideología política, de colores partidistas, pero hubo cosas que no se modificaron y que, ante

AZUA/_FELIX_DE/TRIAS/_EUGENIO/VARGAS_LLOSA/_MARIO/MARSE/_JUAN_/ ESCRITOR/PAZ/_OCTAVIO/SARAMAGO/elpepicul/19900901elpepicul_1/Tes (consultado el 20 de noviembre de 2011)].

${ }^{19}$ Cfr. Jorge Carpizo, El presidencialismo mexicano, México, Siglo XXI, 1978, y Fernando SerRano Migallón, Facultades metaconstitucionales del poder ejecutivo en México, Colección Lecturas Jurídicas, núm. 33, México, UNAM, 2006, disponible en bttp://www. palermo.edu/derecho/publicaciones/sela2006_pdffFernando_Serrano.pdf (consultado el 20 de noviembre de 2011).

${ }_{20}$ Cfr. José Ramón Cossío, Dogmática constitucional y régimen autoritario, México, Fontamara, 1998.

${ }^{21}$ Basten como ejemplos la encarcelación del líder sindical de PEMEX Joaquín Hernández Valencia, el restablecimiento de relaciones políticas con el Vaticano y reconocimiento jurídico a las iglesias, la privatización bancaria y la continuidad de las políticas económicas neoliberales iniciadas en el sexenio de Miguel de la Madrid. 
la ausencia de ese presidente que controlaba todo, se quedaron a la deriva o sin control, a la espera de quien llegara a manejarlas. Como ejemplo, si bien el presidente no era el único que tenía iniciativa de ley (las referidas facultades metaconstitucionales lo incluían), la práctica señalaba que nadie osaba presentar una ley sin la aceptación y aprobación previa presidencial. En la alternancia los diputados y senadores de cualquier partido podían presentar proyectos sin caer en desgracia política y así, ante la ausencia de consensos o de decisión única e incuestionable, comenzaron a multiplicarse las iniciativas y a complicarse la aprobación de leyes. La ausencia a veces de acuerdos generaba restricciones para el ejecutivo.

Felipe de Jesús Calderón Hinojosa (1962), abogado egresado de la Escuela Libre de Derecho, gana las elecciones presidenciales mexicanas de 2006 por el más escaso margen en la historia de este país, el 0,58 por $100^{22}$ de los votos a su favor, lo cual le resta margen de maniobra en su mandato, aunado a que Andrés Manuel López Obrador, que queda en segundo lugar, arguye la existencia de un fraude y se autoproclama «presidente legítimo». Lo anterior provocó - al igual que lo han hecho otros mandatarios a nivel mundial, específicamente George W. Bush- ${ }^{23}$ que buscara la forma de legitimarse en el poder y ejercer su mandato constitucional.

Se había acabado el presidencialismo al disminuirle los poderes el legislativo, al eliminarse la costumbre de las facultades metaconstitucionales, al acabarse las plumas que le justificaban todo, al abrirse la crítica y perderse el poder absoluto. Era necesario encontrar cómo recuperarlo, había necesidad de una emergencia ${ }^{24}$, algo en lo que se apoyara y justificara el uso del poder presidencial, demostrando así quién era el presidente.

La existencia de los poderes dictatoriales no es reciente. Desde el Imperio Romano, su carácter práctico les enseñó que a las emergencias había que combatirlas mediante dictaduras: la concentración del poder en una persona —en agravio o sin perjuicio de las libertades - era la forma

${ }^{22}$ La cifra fue obtenida de la resolución de la Sala Superior del Tribunal Electoral del Poder Judicial Federal dictada el 5 de septiembre del 2006.

${ }_{23}$ George W. Bush y su guerra contra el terrorismo y Al Qaeda. Al respecto véase Kim Lane SChePPele, «Law in a Time of Emergency», Scholarship at Penn Law, paper 55, 2004, disponible en bttp://lsr.nellco.org/upenn_wps/55 (consultado el 20 de noviembre de 2011), en el cual el autor estudia el ataque del 11 de septiembre de 2001 y considera que el gobierno de Estados Unidos sobrerreaccionó en la oportunidad que le dio el ataque, convirtiendo una situación de competencia policíaca en una «guerra» internacional con implicaciones legales internas e internacionales.

24 «Dulces son los usos de la adversidad, los cuales como un sapo, feo y venenoso, portan todavía una preciada joya sobre su cabeza» (William SHAKESPEARE, As you like it). 
de resolverlas. El problema fue que Sila y Julio César convirtieron una institución temporal en algo permanente ${ }^{25}$.

La creación o adopción de una situación dándole carácter de emergencia viene acompañada de la tesis de Carl Schmitt: «Soberano es quien decide en la situación excepcional» ${ }^{26}$, que da origen a la doctrina decisionista. Está sustentado en la idea que el Estado es la unión del pueblo con su gobernante, ya que parte siempre de relaciones amigo-enemigo. «Soberano es quien, con carácter definitivo, decide si la situación es, en efecto, normal» ${ }^{27}$. «El soberano crea esa situación y la garantiza en su totalidad. Él asume el monopolio de la última decisión» ${ }^{28}$. Quien tiene el monopolio en México del manejo de las emergencias, su ponderación, análisis y la consecuente toma de decisión es el presidente. Él es el único facultado por la Constitución para invocar, de conformidad con el art. 29, el estado de excepción.

Una declaratoria de estado de emergencia reconoce la existencia de una situación anómala que faculta al gobernante a romper el orden cotidiano legal y a asumir atribuciones que de otra forma no podría detentar.

Desde diciembre de 2006, el gobierno mexicano le declara la guerra al crimen organizado a través del establecimiento de diversos operativos en los cuales involucró no sólo a la policía federal, sino que le da participación al ejército y a la marina en el combate a diversos grupos delictivos, pero sin decreto legal en los términos establecidos por la Constitución.

El uso de las fuerzas armadas está restringido, según lo que dispone el art. 129 de la Constitución ${ }^{29}$, en tiempos de paz a la disciplina militar, con lo que se podría sostener que la incorporación del ejército a las labores de policía carece de bases jurídicas. Pareciera entonces que se usa el término «guerra al narcotráfico» para dar cabida, precisamente, a la actuación de la milicia.

La guerra tiene diversas definiciones. Desde de la idea de Sun Tzu que consideraba que «la guerra es de vital importancia para el Estado; es el dominio de la vida o de la muerte, el camino hacia la supervivencia o la pérdida del Imperio; es forzoso manejarla bien» ${ }^{30}$, Clausewitz define la guerra como «un duelo a gran escala», «un acto de fuerza para obligar

\footnotetext{
${ }^{25}$ Sobre el tema véase Juan Federico ARRIOLA, Teoría general de la dictadura, México, Trillas, 1994.

${ }^{26}$ Carl SchmitT, op. cit.

27 Ibid.

28 Ibid.

29 Constitución Política de los Estados Unidos Mexicanos, art. 129.

${ }^{30}$ Sun Tzu, El Arte de la Guerra, capítulo I.
} 
al adversario a acatar nuestra voluntad» ${ }^{31}$, pero también desde Aristóteles se señaló a la guerra como «lo contrario a la paz» ${ }^{32}$. Al decir de Héctor Gross Espiell: «La guerra es la negación del derecho a vivir y por eso la paz - que es lo opuesto a la guerra y a la violencia bélica en todas sus formas, así como a la violencia en general en las diferentes modalidades que adopta, todas ellas contrarias a la convivencia deseable entre los hombres- constituye una expresión necesaria, una proyección del reconocimiento del derecho a vivir» ${ }^{33}$.

Carl Schmitt ${ }^{34}$ arguye que el Estado cuenta con el monopolio de la posibilidad de hacer la guerra y, por consiguiente, disponer de la vida de los hombres. El jus belli incluye la doble posibilidad que los miembros del pueblo estés dispuestos a morir por él y a matar a los que sean del bando contrario.

Luigi Ferrajoli considera que la declaración de guerra al narcotráfico es contraria a la naturaleza del Estado de Derecho no sólo respecto a los enemigos, sino también por cuanto ve a los ciudadanos abdicando el Estado a su propia naturaleza, que es impartir la paz. Hablar de guerra es hablar de debilitamiento del Estado y reconocimiento de su ineficacia, y darle a los criminales un rol preponderante que no les corresponde; los colocaría en su mismo rango dándoles carácter de enemigos ${ }^{35}$.

La Ley de Seguridad Nacional no contiene mención alguna a los términos paz o guerra. Pero para que exista guerra legalmente en México se requiere, según la propia Constitución en términos del art. 73, fracción XII ${ }^{36}$, de la declaración que haga el Congreso de la Unión mediante el correspondiente decreto, es decir, no es un acto unilateral volitivo del presidente, necesita de la participación del Congreso y su aprobación mediante la votación correspondiente, lo cual lo restringiría. Por otra parte, si se tratara de una guerra, formalmente se activarían una serie de mecanismos jurídicos internacionales consistentes en tratados internacionales en cuestiones bélicas, como son las referidas en los Convenios de

${ }^{31}$ Carl von Clausewitz, De la Guerra, p. 27.

32 Indudablemente se constituyen en excluyentes, no pueden coexistir.

33 Héctor Gros Espiell, «El derecho humano a la paz», Anuario de Derecho Constitucional Latinoamericano, 2005, disponible en http://www.juridicas.unam.mx/publica/librev/ rev/dconstla/cont/20052/pr/pr7.pdf (consultado el 20 de noviembre de 2011).

${ }^{34}$ Carl Schmitt, El Leviathan en la teoría de Thomas Hobbes, Granada, Comares, 2004.

35 Véase la entrevista que le realiza Carmen Aristegui de CNN en español al jurista italiano, disponible en http://www.youtube.com/watch? $v=F V T 2 f 3 P o 4 f Q$ (consultado el 13 de octubre de 2011).

${ }^{36}$ Constitución Política de los Estados Unidos Mexicanos, art. 73. 
Ginebra y sus protocolos adicionales, el envío de personal de Naciones Unidas, visores o cuerpos de paz, impidiéndole márgenes de maniobra que en su ausencia puede tomar.

Posteriormente, la Presidencia de la República efectuó una corrección sustituyendo la palabra «guerra» por la de «lucha», sin que en realidad permita tampoco esta última el uso de las fuerzas armadas en labores de policía, pues corresponde más a una labor de mantenimiento del orden y prevención que a requerir de las instituciones castrenses.

Pero entonces, ¿cómo es que el ejército y la marina participan en contra del narcotráfico? La justificación se encuentra en la misma Constitución, donde el art. $89^{37}$ le otorga al presidente el cargo de comandante supremo de las Fuerzas Armadas, y las respectivas leyes orgánicas — del Ejército y Fuerza Área mexicanos y de la Armada de México- señalan que les corresponde efectuar las labores que les encomiende el comandante supremo.

El presidente tiene la libertad y puede disponer de las fuerzas armadas a pesar de la disposición prohibitiva - y que deberíamos preponderar por ser en beneficio de las personas-, sin que haya un reclamo jurídico por la violación a la Constitución, bajo varias perspectivas.

En primer término, no hay, por los principios rectores del amparo en México, al igual que ha sucedido con los retenes militares, forma alguna de reclamo abstracto de la inconstitucionalidad por persona alguna por los criterios sostenidos por el poder judicial federal; nadie resentirá la actuación como agravio personal y directo si ya lo padeció, ya está consumado o fue en flagrancia de delito. Como segundo punto, la Suprema Corte de Justicia de la nación ya interpretó el precepto, considerando que es constitucional la actuación del ejecutivo, y usó, para llegar a dicha conclusión, una deducción acerca de la pretensión del legislador ${ }^{38}$ que le permite al presidente decidir libremente.

37 Ibid., art. 89.

${ }^{38}$ Novena época, número de registro: 192082, instancia: Pleno Jurisprudencia, fuente: Semanario Judicial de la Federación y su Gaceta, XI, abril de 2000, materia(s): Constitucional; tesis: P./J. 36/2000, p. 552: «Ejército, fuerza aérea y armada. Si bien pueden participar en acciones civiles en favor de la seguridad pública en situaciones en que no se requiera suspender las garantías, ello debe obedecer a la solicitud expresa de las autoridades civiles a las que deberán estar sujetos, con estricto acatamiento a la Constitución y a las leyes». Del estudio relacionado de los arts. 16, 29, 89, fracción VI, y 129 de la Constitución, así como de los antecedentes de este último dispositivo, se deduce que al utilizarse la expresión «disciplina militar» no se pretendió determinar que las fuerzas militares sólo pudieran actuar, en tiempos de paz, dentro de sus cuarteles, y en tiempos de guerra, perturbación grave de la paz pública o de cualquier situación que ponga a la sociedad en grave peligro o conflicto, fuera de ellos, realizando acciones para superar la situación de 
La otra alternativa, legal para el presidente de la República: la suspensión de garantías contenida en el art. $29^{39}$ de la propia Constitución, que le permitiría, mediante un estado de excepción, actuar sin las limitantes del respeto a los derechos humanos y así combatir frontalmente al narcotráfico.

Esta institución jurídica se puede comparar a los estados de necesidad que en materia penal justifican acciones restándoles el carácter delictivo, o, por otra parte, el homicidio en defensa propia o el robo de famélico, situaciones en las cuales también, a pesar de realizar la conducta típica - homicidio o robo-, el legislador aceptó que se realizaban protegiendo un bien mayor y, por tanto, no las sancionaba.

En las causales del estado de excepción, según la Constitución mexicana, se requiere de una situación de anormalidad que configure una «perturbación grave de la paz pública» o «cualquier otra que ponga a la sociedad en grave peligro o conflicto».

Es obvio que dichas causales son cuestiones subjetivas. No podían hacer una lista enunciativa y limitar, ante los riesgos posibles, a veces incluso inimaginables, al presidente, al que le dejan al final la responsabilidad de decretarlo y asumir las consecuencias de sus actos políticos, jurídicos y sociales ${ }^{40}$.

Encontramos, sin que sea expresamente definido, en la Ley de Delitos de Imprenta (1917) un delito por atacar la paz pública, de la cual se puede inferir que la misma es el respeto a las autoridades del país y abstenerse de propiciar su ridículo y propiciar su obediencia a ciegas ${ }^{41}$, pero en

emergencia en los términos de la ley que al efecto se emita. Es constitucionalmente posible que el ejército, fuerza aérea y armada, en tiempos en que no se haya decretado suspensión de garantías, puedan actuar en apoyo de las autoridades civiles en tareas diversas de seguridad pública. Pero ello de ningún modo pueden hacerlo «por sí y ante sí», sino que es imprescindible que lo realicen a solicitud expresa, fundada y motivada de las autoridades civiles, y de que en sus labores de apoyo se encuentren subordinados a ellas y, de modo fundamental, al orden jurídico previsto en la Constitución, en las leyes que de ella emanen y en los tratados que estén de acuerdo con la misma, atento a lo previsto en su art. 133. Acción de inconstitucionalidad: 1/96, Leonel Godoy Rangel y otros, 5 de marzo de 1996, once votos, ponente: Mariano Azuela Güitrón, secretaria: Mercedes Rodarte Magdaleno. Las cusivas son nuestras.

${ }^{39}$ Constitución Política de los Estados Unidos Mexicanos, art. 29.

${ }^{40} \mathrm{Y}$ por ello, porque asumirá la responsabilidad de sus decisiones, ya hubo una demanda internacional en su contra. La reacción que tuvo al saberse demandado fue considerada desproporcionada.

41 «Art. 3. Constituye un ataque al orden o a la paz pública:

I. Toda manifestación o exposición maliciosa hecha públicamente por medio de discursos, gritos, cantos, amenazas, manuscritos, o de la imprenta, dibujo, litografía, fotografía, 
la jurisprudencia se ha mencionado este mismo concepto en la interpretación de diversas leyes y de nuevo no se definen expresamente, quedando otra vez al arbitrio de la autoridad administrativa usarlo como una justificación abierta y subjetiva:

«En efecto, el servicio de los Ferrocarriles Nacionales está estrechamente ligado a esa existencia por la relación íntima que ese servicio guarda con la economía, con la defensa, con la conservación del orden y de la paz pública, pilares sobre los que descansa el cumplimiento de ese fin superior que concierne a la vida del Estado. Por ello los bienes de ese organismo no pueden estar sujetos a la reglamentación ordinaria del orden común, porque sería entorpecer su servicio, limitarlo e impedir que se realizara de manera continua la satisfacción del servicio que cumplen» ${ }^{42}$.

Entre ambos usos, el de la ley y el posterior usado en la jurisprudencia, no hay relación lógica alguna, lo cual nos sirve para insistir en el carácter discursivo y argumentativo que se le puede dar para argumentar y sostener cualquier peligro.

Hay dos formas de considerar a la Constitución en las emergencias a las que Eric A. Posner y Adrian Vermule ${ }^{43}$ llaman vista cómoda y vista estric-

cinematógrafo, grabado o de cualquier otra manera, que tenga por objeto desprestigiar, ridiculizar o destruir las instituciones fundamentales del país, o con los que se injuria a la nación mexicana o a las entidades políticas que la forman.

II. Toda manifestación o expresión hecha públicamente por cualquiera de los medios de que habla la fracción anterior con la que se aconseje, excite o provoque directa o indirectamente al ejército a la desobediencia, a la rebelión, a la dispersión de sus miembros o a la falta de otro u otros de sus deberes; se aconseje, provoque o excite directamente al público en general a la anarquía, al motín, sedición o rebelión, o a la desobediencia de las leyes o de los mandatos legítimos de la autoridad; se injurie a las autoridades del país con el objeto de atraer sobre ellas el odio, desprecio o ridículo, o con el mismo objeto se ataque a los cuerpos públicos colegiados, al ejército o guardia nacional o a los miembros de aquéllos y éstas, con motivo de sus funciones; se injurie a las naciones amigas, a los soberanos o jefes de ellas, o a sus legítimos representantes en el país, o se aconseje, excite o provoque a la comisión de un delito determinado.

III. La publicación o propagación de noticias falsas o adulteradas sobre acontecimientos de actualidad capaces de perturbar la paz o la tranquilidad de la República o de alguna parte de ella, o de causar el alza o baja de los precios de las mercancías o de lastimar el crédito de la nación o de algún Estado o Municipio, o de los bancos legalmente constituidos.

IV. Toda publicación prohibida por la ley o por la autoridad por causa de interés público, o hecha antes de que la ley permita darla a conocer al público».

42 Sexta época, número de registro: 271200, instancia: Tercera Sala, tesis aislada, fuente: Semanario Judicial de la Federación, cuarta parte, XLII, materia(s): Civil, p. 175, bajo el rubro «Ferrocarriles nacionales, naturaleza de sus bienes».

${ }^{43}$ Eric A. Posner y Adrian Vermule, «Accommodating Emergencies», Chicago Public 
ta. La primera corresponde a que la Constitución debe suspender o relajarse en una emergencia; durante una emergencia el poder debe concentrarse del legislativo y judicial al ejecutivo; los derechos constitucionales se suspenderán de tal forma que el ejecutivo pueda moverse con toda la fuerza en contra de la amenaza, encontrándose justificación en los beneficios de la seguridad nacional.

La violencia, o sea, el poder de coerción, es inseparable de la política, que precede lógica e históricamente al verdadero y propio Estado. El Derecho es un momento del conjunto estatal y, por tanto, no se identifica en rigor con el Estado. Pero dado que el Estado cuando nace subsume la política y la hace un momento interno suyo, junto con la política atrae a sí todo poder de coerción, que, por tanto, deviene, según Max Weber, «monopolio de la violencia legítima». Por ello también el Derecho es inseparable de la coerción ${ }^{44}$.

Dentro de las experiencias históricas mexicanas, y que al final sirven de referente al manejo al ejecutivo en sus decisiones, el poder judicial durante el conflicto bélico de la Segunda Guerra Mundial ajustó sus resoluciones jurisprudenciales a la conveniencia del ejecutivo, lo cual es y le servirá de argumento que le da la libertad de actuar.

Claudio Grossman resume lo anterior de la siguiente forma:

«En tales casos, la autoridad válidamente constituida puede, siempre que sea adecuado a las exigencias de la situación, restringir el goce del conjunto de derechos que deben ser respetados en tiempos de paz. Aunque en teoría es posible justificar restricciones de derechos en el caso en que la vida de una nación se encuentre amenazada, desafortunadamente la práctica muestra que la existencia de una emergencia es a menudo sólo un pretexto para negar arbitrariamente el goce de la plenitud de los derechos civiles y políticos.

En la inmensa mayoría de los casos, la existencia de situaciones de emergencia va acompañada de violaciones masivas y sistemáticas a los derechos humanos. En segundo término, el ejercicio del gobierno con poderes de emergencia acostumbra a las élites políticas a gobernar sin el reconocimiento de los derechos de la población, y, por ende, del libre juego político de consensos y compromisos que produce normalmente el reconocimiento

Law and Legal Theory, Working Paper 48, septiembre de 2003, disponible en bttp://ssm. com/abstract_id=441343 (consultado el día 11 de septiembre de 2010).

${ }^{44}$ Giuseppe Prestipino, «Prefacio (a modo de provocación)», en Edgardo Logiudice, Agamben y el estado de excepción. Una mirada marxista, Buenos Aires, Herramienta Ediciones, 2007. 
de las libertades públicas. En ese escenario se genera también, como resultado de violaciones masivas, una situación de polarización del sistema político, con poblaciones aterrorizadas y resentidas. En numerosas oportunidades las normas de Derecho interno han sido incapaces de proteger a la población frente a las violaciones que generalmente se llevan a cabo en situaciones de emergencia. De ahí la importancia de normas internacionales que permitan que la comunidad internacional actúe en el caso de que se presente tal tipo de situaciones» ${ }^{45}$.

$Y$ es que pareciera que la eficacia de las autoridades, la seguridad nacional y la estabilidad y el orden - la paz - se consiguen y justifican aun sin respeto a los derechos humanos, los cuales pasarían a un segundo plano.

La problemática que encontraría el ejecutivo al declarar el estado de emergencia en el plano de la legalidad es que se autoimpondría límites. $\mathrm{Al}$ encontrarse en la «comodidad» del plano extralegal sin que haya posibilidad de controles que frenen su actuar, difícilmente aceptaría cumplir con las formalidades que se le exigen. Por mencionar algunas, la declaratoria de suspensión de garantías constitucionales en México de inmediato acarrearía consecuencias en el plano interno e internacional: se tendría que cumplir con una serie de requisitos para la declaratoria que incluyen la autorización del poder legislativo, observar un listado de principios aplicables (proporcionalidad, legalidad, racionalidad, proclamación, publicidad y no discriminación), encontraría el ejecutivo derechos humanos que no puede suspender, sus disposiciones legislativas estarían sujetas a un control judicial extraordinario, además el alto comisionado de Naciones Unidas para los Derechos Humanos enviaría visores a comprobar el respeto a los derechos humanos y tendría que cumplir con las recomendaciones que le emitiría el mismo funcionario ${ }^{46}$.

Como cuestiones adicionales, y que no son legales, a la población en México - a pesar de no haber pasado por las vicisitudes de estados de excepción recurrentes como otros países de Latinoamérica- le atemoriza la medida, ya que insistentemente ha escuchado que se trata de la dicta-

${ }^{45}$ Claudio Grossman, «El régimen hemisférico sobre situaciones de emergencia», en Estudios Básicos de Derechos Humanos, vol. I, San José, Instituto Interamericano de Derechos Humanos, 1994.

${ }_{46} \mathrm{Al}$ respecto véase Leandro Despouy, Los derechos humanos y los estados de excepción, México, Instituto de Investigaciones Jurídicas de la UNAM, 1999, disponible en bttp:// www.bibliojuridica.org/libros/libro.htm?l=112 (consultado el 19 de septiembre de 2011). 
dura constitucional ${ }^{47}$, además de que sabe que le implica restricción a sus derechos y no confía en las autoridades.

La excepción puede ser bidireccional para la Critical Legal Studies: si es extralegal, le da a quien la invoca —o aplica — un ámbito o margen mayor de acción, será un elemento de libertad absoluta para acceder a «la sentencia a la que quiero llegar» sin que existan restricciones en su campo, la interpretación y manejo que le puede dar será, mientras detente el monopolio de la fuerza de un país (de la decisión), un instrumento para justificar cualquier acción que realice; si, por el contrario, la excepción es legal, se convertirá en margen de libertad restringida, pero de libertad al fin, en el cual dejará de aplicar las normas que lo circunscriben en la división de poderes y en el respeto a los derechos humanos y estará restringido en la medida de los principios que debe respetar, la temporalidad, la imposibilidad de suspender ciertos derechos, etc.

Por ello, la intencionalidad presidencial, a la que hemos considerado, usando la terminología de Duncan Kennedy, «la sentencia a la que quiere llegar», es de legitimidad en su mandato, ser recordado por las acciones de combate al narcotráfico usando los márgenes que la ley le provee, apuesta en la cual habrá de definirse, en el juicio de la historia y en distintos plazos, si la misma es positiva.

\section{RETÓRICA Y RACIONALIDAD JURÍDICA}

La idea de la racionalidad científica es aceptada como instrumento de convicción, persuasión y seducción a una comunidad o auditorio.

El Derecho de un país no se puede desvincular — al igual que las personas- de sus horizontes de comprensión, formados por sus ideologías, costumbres, intereses, conveniencias, experiencias, cultura, etc., por lo que una norma similar en varios países tendrá recepciones diferentes por su grado de eficacia, de aplicación o de efectividad.

En el caso de la excepción, como se mencionó con anterioridad, desde la construcción de las causas por las cuales se invoca se trata del manejo de la retórica de quién se verá favorecido por esa determinación.

\footnotetext{
47 Véase Diego Valadés, La dictadura constitucional en América Latina, México, UNAM, 1974, disponible en bttp://biblio.juridicas.unam.mx/libros/2/696/1.pdf (consultado el 14 de septiembre de 2010).
} 
Bruce Ackerman ${ }^{48}$ explica que es muy conveniente para un presidente hablar de guerra, que se le dan diversos usos cada vez que se quiere «combatir» algo (guerra contra la pobreza ${ }^{49}$, guerra contra el analfabetismo ${ }^{50}$, guerra contra las infecciones ${ }^{51}$, etc.) y que de esta forma se evita darle el tratamiento que correspondería legalmente. En concreto, crítica la decisión del presidente Bush de enfrentar en una «guerra» al terrorismo y de esa forma actuar sin restricciones cuando debió haber acudido al Congreso e invocar un estado de excepción limitado; considera que la alternativa era reforzar drásticamente las leyes internas - lo cual agradaba menos-y que al llamarle guerra apelaba a la mística del comandante supremo que llamaba al sacrificio en aras del bien de la nación y se evitaba los papeleos legales que implicaban tratar al terrorismo como un mero crimen, y caracteriza a lo anterior como la cobertura retórica para acciones unilaterales de constitucionalidad cuestionable. De esta forma, la excepción se construye a través de aquellos argumentos en que se sustenta la necesidad de la aplicación de medidas más drásticas que las usadas en los tiempos de normalidad.

Por ejemplo, en el manejo del argumento de la seguridad nacional que es, en realidad, parte de la misma construcción argumentativa para sostener la necesidad de invocar la excepción, es decir, sigue siendo justificativa - cualquier cosa resulta más conveniente que la legalidad en sí misma. Si al auditorio se le lleva a la necesidad de comparar entre sufrir inseguridad o ilegalidad preferirá indudablemente la segunda.

$\mathrm{Y}$ es que en la excepción se da un margen para lograr convencer, persuadir o seducir al auditorio de lo que sea necesario o, mejor dicho, conveniente para los detentadores del poder - y de alguna forma de la «verdad oficial» - , tanto de manera previa como posterior. En 1994, el primer día del año, se dio el denominado «levantamiento zapatista» en Chiapas; en esa fecha el presidente actuó como comandante supremo de las Fuerzas Armadas y, sin cubrir ninguna formalidad legal, ordenó al ejército defen-

48 Bruce ACKERMAn, «This is not a War», The Yale Law Journal, vol. 113, num. 8 (junio de 2004).

49 Ángeles Palacios Escobar dice: «La prioridad del gobierno mexicano en los últimos años, y en particular el objetivo central de la política social, ha sido el combate a la pobreza. Así, la guerra contra la pobreza en México nace en 1989 con el Programa Nacional de Solidaridad, y posteriormente, en el sexenio siguiente continúa esta tendencia con el programa Educación, Salud y Alimentación, y actualmente con el programa Oportunidades», disponible en bttp://www.rolandocordera.org. $m x /$ pol_social/caracteristicas.btm" $\backslash$ " ftn1.

${ }^{50} \ll \mathrm{Y}$ por eso tenemos que emprender ya la guerra contra el analfabetismo» (rector José Narro Robles, discurso en conmemoración del centenario de la UNAM).

51 Sandra VALDERRAMA, «Estrategias para no perder la guerra contra las enfermedades infecciosas», Revista MED, disponible en http://redalyc.uaemex.mx/pdf/910/91016120.pdf. 
derse y repeler el ataque de los rebeldes; dicha conducta fue sustentada como jurídicamente correcta desde el Instituto de Investigaciones Jurídicas de la UNAM mediante la obra La rebelión en Chiapas y el Derecho, en donde Mario Melgar Adalid sostuvo:

«Conforme al texto del art. 89, el ejecutivo federal tiene frente a sí un ámbito de acción ejecutiva inmediata, como el que aconsejaba la prudencia en ese momento, pero dentro de límites constitucionales, pues el ejecutivo tiene que garantizar tanto las garantías individuales como la división de poderes» ${ }^{52}$.

Y de esta forma dicho autor justificó el actuar mediante argumentos en los que usa como centro a la prudencia, con una excepción extralegal.

Otro ejemplo es que se pensó entrar a la moratoria de pagos internacionales a través del uso del ejecutivo de facultades extraordinarias para legislar como única alternativa viable:

¿Cuál fue el momento más difícil para el secretario de Hacienda en estos dos años? La primera parte de 1995, cuando estuvimos en una situación de total incertidumbre respecto a la posibilidad del país de poder cumplir sus obligaciones frente al exterior y ante la amenaza inminente del colapso financiero. Amenazas reales. ¿Qué tan cerca estuvimos del desastre total? Muy cerca [...] Muy cerca [...] Sé que es muy difícil decirle a alguien que está muy golpeado, que tuvo un accidente [...] Decirle cuando sale de terapia intensiva, con fracturas, dolores inmensos [...] Es muy difícil decirle ¡hombre, te fue muy bien, pudo haber sido mucho peor! Pero sí, estuvimos muy cerca de irnos a un escenario mucho peor. ¿Mucho peor? La amenaza de irnos a una suspensión de pagos. Estuvimos muy cerca. Esto hubiera dislocado las actividades económicas. Hubiera habido una suspensión total de financiamiento del exterior, que en una economía globalizada hubiese significado la parálisis económica, una recesión más grave. El PIB cayó casi un 7 por 100 en 1995. A lo mejor se hubiera ido al doble. No sé. Pero sí sé que una corrida sobre el sistema financiero mexicano hubiera significado también una ruptura de la interpelación económica diaria que vivimos, una interrupción de los sistemas de pago que hubiera significado un colapso en la economía real. Fueron dos amenazas concretas que vivimos en 1995. ¿Qué tan cercanas? Muy, muy cercanas. Hubo momentos en que si no se

52 Mario Melgar Adalid, «El conflicto en Chiapas y la suspensión de las garantías individuales», en La rebelión de Chiapas y el Derecho, México, Instituto de Investigaciones Jurídicas de la UNAM, 1994. 
resolvían algunas cuestiones en materia de financiamiento externo y de no suspensión de las líneas de crédito, pues hubiéramos tenido que irnos al incumplimiento, al control de cambios, a la suspensión de garantías individuales. ¡Suspensión de garantías individuales! Hubiera sido la única base jurídica para poder posponer, por ejemplo, el pago de los Tesobonos [...] Fueron días y semanas de mucha angustia. ¿Qué pasaba por la cabeza del secretario de Hacienda? Estábamos enfrentando una situación que hubiera podido desembocar en algo caótico. Evidentemente pensaba que las repercusiones económicas iban a tener un impacto en lo social, en materia de seguridad personal ${ }^{53}$.

Nos dice Vázquez Irizarry:

«Por último, debemos considerar también el carácter político de la emergencia. Por más que se pretenda enmarcar la declaración de emergencia en un marco normativo, sea el mismo de carácter constitucional o estatutario, al final es posible afirmar que no estamos ante un problema "legal". Más bien parece que enfrentamos una decisión de tipo administrativo gubernamental que al final descansa en elementos discrecionales de quien tiene la facultad y los mecanismos para actuar. Al final, los órganos responsables políticamente necesariamente tendrán que tomar la decisión epistémica de si existe una emergencia que justifique la invocación de los poderes de emergencia.

El problema con lo anterior reside en cómo controlar el uso retórico de la emergencia como excusa para lograr por la vía extraordinaria lo que el proceso político legal ordinario no hubiera permitido. En este sentido no es inusual que los gobernantes hagan uso de un discurso de la crisis y la emergencia para generar cohesión social detrás de sus políticas o bien querer imponer la "lógica" de las mismas. El problema es cuando se pretende utilizar la misma narrativa para justificar la activación formal de poderes especiales ${ }^{54}$.

Se demuestra con lo anterior que con una argumentación y manejo del lenguaje jurídico existe la posibilidad, sin que se decrete con las formalidades contempladas por el art. 29 de la Constitución, de un estado de excepción al que llamaremos de facto, y se diferencia del que llamaremos de iure en el que se cumplen los requisitos legales. Cuando el ejecutivo de un país

53 Ciro Gómez Leyva, «Zedillo a dos años», en Reforma, entrevista con Guillermo Ortiz, viernes, 15 de noviembre de 1996. Las cursivas corresponden a las preguntas del reportero.

${ }^{54}$ William VazQuez IrIZARRY, op. cit., p. 65. 
cuenta con la posibilidad de centralizar el lenguaje sin que existan los equilibrios correspondientes podrá usar flexiblemente la ley a través de monopolizar su interpretación y manejo público.

La existencia de facto de un estado excepcional sin la declaratoria formal correspondiente es sintomática de un país con instituciones débiles y controles jurídicos laxos; se da cuando las decisiones tomadas por el ejecutivo - por encima de la ley, de las instituciones y sin reclamo alguno de cualquier otra autoridad - no tienen mecanismos de freno o contrapeso. El riesgo, según manifiestan Posner y Vermule ${ }^{55}$, es que se genere un ratchet $^{56}$. Cada vez que se restringen derechos en un estado de excepción, de facto o de iure, la doctrina, la jurisprudencia y aun la costumbre aceptan implícitamente que dicho derecho ha quedado menoscabado, y como no hay un regreso a la normalidad con formalismos, dicho derecho, ya sin la situación excepcional, se quedará permanentemente asî́ ${ }^{57}$. Recordemos, al igual que cuando nos referíamos a los arts. 89 y 129 , que no hay mecanismos de freno en los otros poderes en contra de los actos del ejecutivo y tampoco que pueda usar la población.

De esta forma podemos establecer que, cuando la norma jurídica no nos es útil para construir los argumentos de convicción, persuasión o seducción, la excepción nos dará un margen nuevo y más amplio de manejo, máxime cuando podemos contar también con el que juzgará el argumento y que le dará más elementos de verdad al auditorio.

Debemos asumir las críticas, como discusión del auditorio, que se han efectuado al combate al narcotráfico, la existencia de más de 100.000 muertos - a las que la autoridad ha desdeñado considerándolos bajas colaterales (léxico castrense)- - Human Rights Watch ha considerado que no se han logrado ni derechos ni seguridad ${ }^{58}$ y este combate ha enfrentado sistemáticamente al presidente con todos los sectores, sin lograr ningún resultado palpable; el efecto de Hidra y la pulverización de los cárteles y la escalada de violencia no traen buenos augurios.

55 Eric A. Posner, op. cit.

${ }^{56}$ Un ratchet es un mecanismo que permite a un engranaje girar en un sentido, pero que impide hacerlo en el sentido inverso o contrario, pues es trabado con dientes en forma de sierra. También se le conoce como fleje, trinquete, etc.

57 En México durante la Segunda Guerra Mundial se suspendieron garantías individuales (por su denominación en aquella época). Diversas disposiciones fueron emitidas y, levantado el estado de excepción, el Congreso las determinó, con el beneplácito o consentimiento del poder judicial federal, como derecho ordinario; como ejemplo, cinco décadas después seguían vigentes los decretos que congelaban el pago de rentas en el Distrito Federal.

58 bttp://www.hrw.org/node/102793/section/1. 
Decretar un estado de excepción debe buscar, en todos los supuestos y bajo cualquier óptica, salir de la situación de anormalidad. Cuando esto no es posible cabe revisar las causas por las cuales se invocó; si las mismas eran irreales o con una intencionalidad diferente provocará, necesariamente, que se mantenga dicha situación. Así se consolidaron, constitucionalmente, dictaduras.

\section{CONCLUSIÓN}

Como se ha visto, epistemológicamente el concepto de Derecho no es universalmente reconocido y sus variables se dan de inicio por las distintas ideologías y formas de pensamiento.

A pesar de no haber abordado temas de eficacia en su aplicación, cada lugar variará, como parte del horizonte de comprensión, en el papel que le asigna al Derecho como elemento social.

Walter Benjamin elaboró su tesis VIII para criticar a Carl Schmitt en su justificación de la existencia de la excepción de la siguiente forma: «La tradición de los oprimidos nos enseña que el "estado de excepción" en el que vivimos es sin duda la regla» ${ }^{59}$. Con lo cual se manifestaba contra el desuso de las normas.

Cabe preguntarse ahora acerca del Derecho, ¿serán normas o excepciones?

\section{BIBLIOGRAFÍA}

ACKerman B., «This is not a War», The Yale Law Journal, vol. 113, num. 8 (junio de 2004).

Arriola J. F., Teoría General de la Dictadura, México, Universidad Panamericana, 1994.

Benjamin, W., Obras, libro I, vol. 2, Madrid, Abada, 2008.

Carpizo J., El presidencialismo mexicano, México, Siglo XXI, 1978.

Constitución Política de los Estados Unidos Mexicanos, México.

Cossío y Díaz, J. R., Dogmática constitucional y régimen autoritario, México, Fontamara, 1998.

Despouy, L., Los derechos humanos y los estados de excepción, México, Instituto de Investigaciones Jurídicas de la UNAM, 1999.

59 Walter Benjamin, Obras, libro I, vol. 2, Madrid, Abada, 2008. 
Ferrajoli, L., Derechos y garantías. La Ley del más débil, Madrid, Trotta, 1999.

Gros Espiell, H., «El derecho humano a la paz», Anuario de Derecho Constitucional Latinoamericano, 2005.

Gross, O., y Ní Aoláin, F., Law in times of crisis. Emergency powers in theory and practice, Cambridge, Cambridge University Press, 2006.

Grossman, C., «El régimen hemisférico sobre situaciones de emergencia», en Estudios Básicos de Derechos Humanos, vol. I, San José, Instituto Interamericano de Derechos Humanos, 1994.

Lane Scheppele, K., «Law in a Time of Emergency», Scholarship at Penn Law, paper 55, 2004.

Melgar Adalid, M., «El conflicto en Chiapas y la suspensión de las garantías individuales», en La rebelión de Chiapas y el Derecho, México, Instituto de Investigaciones Jurídicas de la UNAM, 1994.

Posner, E. A., y Vermule, A., «Accommodating Emergencies», Chicago Public Law and Legal Theory, Working Paper 48, septiembre de 2003.

Prestipino, G., «Prefacio (a modo de provocación)», en Edgardo Logiudice, Agamben y el estado de excepción. Una mirada marxista, Buenos Aires, Herramienta Ediciones, 2007.

Schmitt, C., Teología política, Madrid, Trotta, 2009.

Serrano Migallón, F., Facultades metaconstitucionales del poder ejecutivo en México, Colección Lecturas Jurídicas, núm. 33, México, UNAM, 2006.

Sun Tzu, El Arte de la Guerra.

Valadés, D., La dictadura constitucional en América Latina, México, UNAM, 1974.

VÁZQUEZ IRIZARRY, W., Excepción y necesidad: la posibilidad de una teoría general de la emergencia, Chile, SELA, 2010.

Von Clausewitz, C., De la guerra, Agebe, 2004. 